\title{
Are Dose and Duration of Methamphetamine Abuse Associated with Psychotic Symptoms?
}

\author{
Seyed Alireza Sadjadi ${ }^{1}$, Amir Rezaei Ardani ${ }^{10}{ }^{1}$, Ali Asadi ${ }^{2}$ and Mahboubeh Eslamzadeh (iD ${ }^{1,{ }^{*}}$ \\ ${ }^{1}$ Psychiatry and Behavioral Sciences Research Center, Mashhad University of Medical Sciences, Mashhad, IR Iran \\ ${ }^{2}$ Department of Clinical Psychology, Shahrood Branch, Islamic Azad University, Shahrood, IR Iran \\ "Corresponding author: Psychiatry and Behavioral Sciences Research Center, Mashhad University of Medical Sciences, Mashhad, IR Iran. Tel: +98-5137112540, Email: \\ Eslamzadehmh@mums.ac.ir
}

Received 2019 November 14; Revised 2020 February 10; Accepted 2020 February 19.

\begin{abstract}
Background: Regarding the high prevalence of methamphetamine (MA) abuse among the youth population and its consequences, especially psychiatric problems.

Objectives: This research aimed to investigate the relationship between the rate and severity of methamphetamine associated psychotic symptoms with duration and dose of methamphetamine in Iranian abusers.

Patients and Methods: The statistical population of this descriptive-correlational study consisted of all methamphetamine abusers who referred to Ibn-e-Sina Psychiatric Hospital in Mashhad city. The cases were selected through convenience sampling method. The research instrument included the demographic questionnaire and positive and negative symptoms scale. Data were analyzed by descriptive statistics and Pearson correlation coefficient through SPSS software.

Results: The participants included 100 amphetamine abusers (80 men and 20 women) with the mean age of $30.84 \pm 6.62$ years. There were significant relationships between dose of amphetamine abuse and positive $(\mathrm{P}=0.004)$ and negative psychotic symptoms $(\mathrm{P}=0.04)$, while the duration of amphetamine abuse did not have any significant relationships with positive and negative psychotic symptoms and general psychopathology $(\mathrm{P}>0.05)$.

Conclusions: The findings indicated dose-related psychosis in amphetamine abusers while the duration of abuse did not have any significant relationships with psychotic symptoms and general psychopathology.
\end{abstract}

Keywords: Dose-Response Relationship, Drug, Methamphetamine, Psychotic Symptoms, Substance-Related Disorders

\section{Background}

Methamphetamines are the most prevalent synthetic stimulants worldwide (1). Abuse of these neuro stimulants is associated with various physical and psychiatric problems such as mood disorders, psychosis (2,3), cognitive impairment $(4,5)$, sexual dysfunction, and violent behavior (6).

Amongst adverse effects of methamphetamine abuse, methamphetamine associated psychotic symptoms due to the excessive release of dopamine (7) can have an impact on the quality of life and health conditions, which may lead to a heavy burden on individuals and society $(8,9)$.

The different studies have reported various rates of psychotic symptoms among methamphetamine abusers in a wide range between $13 \%$ to $60 \%(10,11)$.

The high rate of psychosis in methamphetamine abusers motivates the researchers and practitioners to investigate the associated factors of methamphetamineinduced psychotic symptoms to reduce the risk of psychosis among these abusers. Based on the evidence, it seems that different factors such as chronic dependence on methamphetamine (12), the severity of dependence (13), lower onset age (14) and dose of the agent (15) are the risk factors that increase the probability of methamphetamine associated psychotic symptoms in abusers.

Despite the mentioned associated factors, there is some evidence that suggests contrasting findings. For example, some cases with long dependence and frequent abuse of methamphetamines do not show any psychotic symptoms, while some with limited abuse of methamphetamine experience long-lasting psychosis $(16,17)$. These controversies indicate the necessity to conduct more studies in different countries. 


\section{Objectives}

Regarding the high prevalence rate of amphetamine abuse in Iran especially among youth population and distinguishing the risk factors of methamphetamine associated psychosis while reducing harmful consequences $(18$, 19), we aimed to investigate the relationship between the rate and severity of methamphetamine associated psychotic symptoms with duration and dose of methamphetamine in Iranian abusers.

\section{Patients and Methods}

The statistical population of this descriptivecorrelational study consisted of all methamphetamine abusers who referred to Ibn-e-Sina Psychiatric Hospital in Mashhad city (the second most populous city of Iran). The cases were selected through convenience sampling method.

Inclusion criteria: (1) abusers aged 18 - 45 years who referred to Ibn-e-Sina Psychiatric Hospital in Mashhad city (hospitalized or out-patient) with positive amphetamine test; (2) presence of psychosis on admission; (3) receiving a diagnosis of amphetamine-induced psychosis based on DSM-IV criteria; (4) written consent form to participate in research (by patient or parents).

Exclusion criteria: presence of comorbidity, history of psychotic disorders before amphetamine abuse.

\subsection{Research Instrument}

\subsubsection{Demographic Form}

This form included demographic variables such as age, gender, marital status, occupational status, history of physical illness, history of psychiatric hospitalization.

\subsubsection{Positive and Negative Symptoms Scale}

This is a 30-question scale that responded in a 5-degree Likert system. It has 5 subscales included: negative symptoms (8 questions), disassociation (7 questions), positive symptoms (6 questions), arousal (4 questions), anxiety, and depression (5 questions). This scale has good validity (Cronbach alpha $=0.77)$, and it is normalized for the Iranian population $(20,21)$.

\subsection{Ethical Approval}

This research is approved by the vice-chancellor of Islamic Azad University, the branch of Shahrood concerning ethical considerations, the aim of the research was explained for parents of patients or patients who referred to Ibn-e-Sina Hospital, and the cases have participated voluntarily.

\subsection{Statistical Analysis}

Data were analyzed by descriptive statistics such as mean, standard deviation and mode, etc. and Pearson correlation coefficient through SPSS software.

\section{Results}

The participants included 100 amphetamine abusers ( 80 men and 20 women) with the mean age of $30.84 \pm$ 6.62 years. Demographic characteristics of participants indicated that $43 \%$ of participants were married while $37 \%$ and $20 \%$ of them were single and divorced, respectively. In terms of educational level, $15 \%$ of them were educated at the elementary level, 37 of them had intermediate level while $40 \%$ and $8 \%$ of participants had a diploma and higher-level, respectively. Also, $70 \%$ of amphetamine abusers were jobless. Also, $13 \%$ of them had a history of admission in a psychiatric hospital, and $1 \%$ had a positive family history of psychiatric disorder.

Table 1 shows the descriptive variables related to psychopathology, psychotic symptoms, and amphetamine abuse.

Tables 2 and 3 present the correlation between duration and dose of amphetamine abuse with positive and negative psychotic symptoms and general psychopathology.

As seen in the above tables, there were significant relationships between dose of amphetamine abuse and positive $(\mathrm{P}=0.004)$ and negative psychotic symptoms $(\mathrm{P}=$ 0.04) while the duration of amphetamine abuse did not have any significant relationships with positive and negative psychotic symptoms and general psychopathology ( $\mathrm{P}$ $>0.05)$.

\section{Discussion}

Based on the present study which was conducted on 100 amphetamine abusers, there were no significant relationships between duration of amphetamine abuse and positive and negative symptoms and general psychopathology despite the long duration of abuse among almost of patients (longer than 20 months). This is while the findings indicated that the dose of amphetamine had a stronger correlation with psychotic symptoms.

Similar to the present study, Ma et al. in China evaluated the risk of psychiatric symptoms in 1277 methamphetamine abusers (1069 men and 160 women) through positive and negative symptoms scale, Hamilton anxiety inventory, and Beck depression inventory. In terms of duration of amphetamine abuse, the cases were divided into three groups: < 1 year, 1-5 years, and five years. The findings 


\begin{tabular}{|c|c|c|c|c|}
\hline Variable & Mean & Standard Deviation & Maximum & Minimum \\
\hline Severity of positive symptoms & 22.70 & 6.48 & 37 & 11 \\
\hline Severity of negative symptoms & 18.47 & 5.73 & 37 & 8 \\
\hline General psychopathology & 39.37 & 8.74 & 70 & 19 \\
\hline Duration of amphetamine abuse (month) & 20.55 & 12.56 & 60 & 2 \\
\hline Dose of amphetamine abuse (score 1 - 4) & 1.86 & 0.93 & 4 & 1 \\
\hline
\end{tabular}

Table 2. The Correlation Between Duration of Amphetamine Abuse with Positive and Negative Psychotic Symptoms and General Psychopathology

\begin{tabular}{lcc}
\hline \multirow{2}{*}{ Variable } & \multicolumn{2}{c}{ Duration of Amphetamine Abuse } \\
\cline { 2 - 3 } & Pearson Coefficient & P Value \\
\hline Positive psychotic symptoms & 0.12 & 0.23 \\
Negative psychotic symptoms & 0.12 & 0.23 \\
General psychopathology & 0.04 & 0.72 \\
\hline
\end{tabular}

Table 3. The Correlation Between Dose of Amphetamine Abuse with Positive and Negative Psychotic Symptoms and General Psychopathology

\begin{tabular}{lcc}
\hline \multirow{2}{*}{ Variable } & \multicolumn{2}{c}{ Dose of Amphetamine Abuse } \\
\cline { 2 - 3 } & Pearson Coefficient & P Value \\
\hline Positive psychotic symptoms & 0.28 & 0.004 \\
Negative psychotic symptoms & 0.20 & 0.04 \\
General psychopathology & 0.15 & 0.13 \\
\hline
\end{tabular}

showed that the prevalence of psychotic symptoms in 3 durations of MA abuse was $16.5 \%, 17.2 \%$, and $23.5 \%$ respectively. Like our study though, the rate of any type of psychiatric symptoms increased significantly with longer duration of abuse (12).

In addition, Su et al. assessed the demographic variables and risk factors of methamphetamine-induced psychosis (MAP) in 1685 abusers. Most of them are men aged 30 years or above with limited education. Furthermore, 72.3\% of them had an abuse duration of more than 3 months. In terms of dose, $47.8 \%$ of them used $\geq 0.2$ gram MA per occasion, and $17 \%$ of abusers experienced psychotic symptoms even in abstinence period. The results showed that higher dose of MA ( $\geq 0.2$ gram) and longer duration $(>3$ months) were associated with MAP. These findings support the present study (22).

There was an inconsistency between the conducted studies about years of abuse and methamphetamine associated psychosis (MAP). Almost of studies reported that there was not a significant association between duration of abuse and MAP, although some of the studies found that duration of abuse longer than 4 years significantly increases the rate of MAP (23).

On the other hand, it seems that the amount of am- phetamine abuse is associated with MAP and psychiatric symptoms greater than the duration of abuse, similar to our research $(13,24)$.

McKetin et al. in their research which was published in 2013 assessed 276 participants aged 16 years or older (mean age: 31.7 years) who received the diagnosis of methamphetamine dependency through Brief Psychiatric Rating Scale to evaluate hallucinations, suspiciousness and unusual thought content and Opiate Treatment Index to assess the amount methamphetamine abuse in the past month. The majority of these participants were male, jobless, and single, as in our research. The findings showed that experiencing psychotic episodes was associated with a higher dose of amphetamine abuse ( $>16$ days of abuse in the past month) strongly similar to our research; although the weight of the methamphetamine was not measured in the McKetin et al. study (15).

Another study conducted by Salo et al. on 190 methamphetamine abusers indicated that there was not any significant relationship between MA-induced paranoia and demographic variables of methamphetamine abuse including duration, age of first abuse, and mean daily dose of MA (17).

Regarding to the high prevalence rate of methamphetamine-induced psychosis, violent behaviors and suicidality in methamphetamine abusers, assessment to identify risk-factors among these patients is necessary (25-27).

\subsection{Limitations}

Our research has some limitations as any crosssectional studies such as:

- Small sample size.

- Participants who referred to one center.

- Lack of long term follow-ups.

\subsection{Conclusions}

Based on the findings, there were significant relationships between dose of amphetamine abuse and positive and negative psychotic symptoms, while the duration of 
amphetamine abuse did not have any significant relationships with positive and negative psychotic symptoms and general psychopathology. This finding emphasizes the psychiatric evaluation of heavy abusers.

\section{Acknowledgments}

This research was approved and supported financially by Shahrood branch, Islamic Azad University.

\section{Footnotes}

Authors' Contribution: Conception and designing the study and manuscript evaluation: Seyed Alireza Sadjadi and Amir Rezaei Ardani; data collection and manuscript writing: Ali Asadi and Mahboubeh Eslamzadeh; manuscript writing and data interpretation: Seyed Alireza Sadjadi and Amir Rezaei Ardani; supervision and conception: Seyed Alireza Sadjadi, Mahboubeh Eslamzadeh.

Conflict of Interests: The authors declare no conflict of interest with the results.

Ethical Approval: This research was a thesis that was approved by the vice-chancellor of Shahrood Branch, Islamic Azad University, Shahrood, Iran and is registered in Iranian Research Institute for Information Science and Technology, Ministry of Science, Research, and Technology (MSRT), Iran (Code: 263151).

Funding/Support: Shahrood Branch, Islamic Azad University, Shahrood, Iran.

\section{References}

1. Rezaei Ardani A, Motamedi Nasab A. Methamphetamine psychosis, the efficacy of atypical antipsychotics. Rev Clin Med. 2015;2(1):9-14.

2. Meredith CW, Jaffe C, Ang-Lee K, Saxon AJ. Implications of chronic methamphetamine use: A literature review. Harv Rev Psychiatry. 2005;13(3):141-54. doi: 10.1080/10673220591003605. [PubMed: 16020027].

3. Grant KM, LeVan TD, Wells SM, Li M, Stoltenberg SF, Gendelman HE, et al. Methamphetamine-associated psychosis. J Neuroimmune Pharmacol. 2012;7(1):113-39. doi: 10.1007/s11481-011-9288-1. [PubMed: 21728034]. [PubMed Central: PMC3280383].

4. Khalkhali M, Golshahi M, Hasandokht T, Kafie M, Zare R. Cognitive functioning in Schizophrenia, methamphetamine-induced psychotic disorder, and healthy people: A comparative study. Adv Biomed Res. 2018;7:123. doi: 10.4103/abr.abr_14_18. [PubMed: 30211136]. [PubMed Central: PMC6124221].

5. Herbeck DM, Brecht ML. Substance use and mental health characteristics associated with cognitive functioning among adults who use methamphetamine. I Addict Dis. 2013;32(1):11-25. doi: 10.1080/10550887.2012.759871. [PubMed: 23480244]. [PubMed Central: PMC3601587].
6. McKetin R, Lubman DI, Najman JM, Dawe S, Butterworth P, Baker AL. Does methamphetamine use increase violent behaviour? Evidence from a prospective longitudinal study. Addiction. 2014;109(5):798806. doi: 10.1111/add.12474. [PubMed: 24400972].

7. Cruickshank CC, Dyer KR. A review of the clinical pharmacology of methamphetamine.Addiction.2009;104(7):1085-99. doi:10.1111/j.13600443.2009.02564.x. [PubMed: 19426289].

8. Kittirattanapaiboon $\mathrm{P}$, Mahatnirunkul S, Booncharoen $\mathrm{H}$, Thummawomg P, Dumrongchai U, Chutha W. Long-term outcomes in methamphetamine psychosis patients after first hospitalisation. Drug Alcohol Rev. 2010;29(4):456-61. doi: 10.1111/j.14653362.2010.00196.x. [PubMed: 20636664].

9. Artenie AA, Bruneau J, Zang G, Lesperance F, Renaud J, Tremblay $J$, et al. Associations of substance use patterns with attempted suicide among persons who inject drugs: Can distinct use patterns play a role? Drug Alcohol Depend. 2015;147:208-14. doi: 10.1016/j.drugalcdep.2014.11.011. [PubMed: 25487226].

10. Lecomte T, Dumais A, Dugre JR, Potvin S. The prevalence of substance-induced psychotic disorder in methamphetamine misusers: A meta-analysis. Psychiatry Res. 2018;268:189-92. doi: 10.1016/j.psychres.2018.05.033. [PubMed: 30041133].

11. McKetin R, McLaren J, Lubman DI, Hides L. The prevalence of psychotic symptoms among methamphetamine users. Addiction. 2006;101(10):1473-8. doi: 10.1111/j.1360-0443.2006.01496.x. [PubMed: 16968349].

12. Ma J, Sun XJ, Wang RJ, Wang TY, Su MF, Liu MX, et al. Profile of psychiatric symptoms in methamphetamine users in China: Greater risk of psychiatric symptoms with a longer duration of use. Psychiatry Res. 2018;262:184-92. doi: 10.1016/j.psychres.2018.02.017. [PubMed: 29453037].

13. Ding Y, Lin H, Zhou L, Yan H, He N. Adverse childhood experiences and interaction with methamphetamine use frequency in the risk of methamphetamine-associated psychosis. Drug Alcohol Depend. 2014;142:295-300. doi: 10.1016/j.drugalcdep.2014.06.042. [PubMed: 25064022]

14. Kalayasiri R, Mutirangura A, Verachai V, Gelernter J, Malison RT. Risk factors for methamphetamine-induced paranoia and latency of symptom onset in a Thai drug treatment cohort. Asian Biomed. 2010;3(6):635-43.

15. McKetin R, Lubman DI, Baker AL, Dawe S, Ali RL. Dose-related psychotic symptoms in chronic methamphetamine users: Evidence from a prospective longitudinal study.JAMA Psychiatry. 2013;70(3):31924. doi: 10.1001/jamapsychiatry.2013.283. [PubMed: 23303471].

16. Akiyama K, Saito A, Shimoda K. Chronic methamphetamine psychosis after long-term abstinence in Japanese incarcerated patients. Am J Addict. 2011;20(3):240-9. doi: 10.1111/j.1521-0391.2011.00124.x. [PubMed: 21477052].

17. Salo R, Fassbender C, Iosif AM, Ursu S, Leamon MH, Carter C. Predictors of methamphetamine psychosis: History of ADHD-relevant childhood behaviors and drug exposure. Psychiatry Res. 2013;210(2):52935. doi: 10.1016/j.psychres.2013.06.030. [PubMed: 23896355]. [PubMed Central: PMC3818411]

18. Zarrabi H, Khalkhali M, Hamidi A, Ahmadi R, Zavarmousavi M. Clinical features, course and treatment of methamphetamine-induced psychosis in psychiatric inpatients. BMC Psychiatry. 2016;16:44. doi: 10.1186/s12888-016-0745-5. [PubMed: 26911516]. [PubMed Central: PMC4766712].

19. Mehrpour O. Methamphetamin abuse a new concern in Iran Daru. 2012;20(1):73. doi: 10.1186/2008-2231-20-73. [PubMed: 23351837] [PubMed Central: PMC3556003].

20. Kay SR, Sevy S. Pyramidical model of schizophrenia. Schizophr Bull. 1990;16(3):537-45. doi:10.1093/schbul/16.3.537. [PubMed: 2287938].

21. Ghamari-Givi H, Molavi P, Heshmati RMA. [Exploration of the factor structure of positive and negative syndrome scale in schizophrenia spectrum disorders]. J Clin Psychol. 2010;2(2):1-10. Persian. 
22. Su MF, Liu MX, Li JQ, Lappin JM, Li SX, Wu P, et al. Epidemiological characteristics and risk factors of methamphetamineassociated psychotic symptoms. Front Psychiatry. 2018;9:489. doi: 10.3389/fpsyt.2018.00489. [PubMed: 30369888]. [PubMed Central: PMC6194209].

23. Arunogiri S, Foulds JA, McKetin R, Lubman DI. A systematic review of risk factors for methamphetamine-associated psychosis. Aust NZJPsychiatry. 2018;52(6):514-29. doi: 10.1177/0004867417748750. [PubMed: 29338289].

24. Sulaiman AH, Said MA, Habil MH, Rashid R, Siddiq A, Guan NC, et al. The risk and associated factors of methamphetamine psychosis in methamphetamine-dependent patients in Malaysia. Compr Psychiatry. 2014;55 Suppl 1:S89-94. doi: 10.1016/j.comppsych.2013.01.003. [PubMed: 23433219].
25. Lamyai W, Pono K, Indrakamhaeng D, Saengsin A, Songhong N, Khuwuthyakorn $\mathrm{P}$, et al. Risks of psychosis in methamphetamine users: Cross-sectional study in Thailand.BMJ Open. 2019;9(10). e032711. doi: 10.1136/bmjopen-2019-032711. [PubMed: 31615802]. [PubMed Central: PMC6797321].

26. McInnis P, Lee A. Methamphetamine use in an early psychosis service: A cross-sectional retrospective cohort study. Australas Psychiatry. 2019;27(4):383-7. doi: 10.1177/1039856219859811. [PubMed: 31264898].

27. Khoramizadeh M, Effatpanah M, Mostaghimi A, Rezaei M, Mahjoub A, Shishehgar S. Treatment of amphetamine abuse/use disorder: A systematic review of a recent health concern. Daru. 2019;27(2):743-53. doi: 10.1007/s40199-019-00282-3. [PubMed: 31228128]. [PubMed Central: PMC6895313]. 